\title{
ORIGINAL CONTRIBUTIONS
}

\section{ALTERED OXIDANT-ANTIOXIDANT STATUS IN NON-OBESE MEN WITH MODERATE ESSENTIAL HYPERTENSION}

\author{
H. NANDEESHA, V. SATHIYAPRIYA, ZACHARIAH BOBBY, P. PAVITHRAN ${ }^{\star}$ APARNA AGRAWAL**, \\ N. SELVARAJ
}

\section{ABSTRACT}

BACKGROUND: Although a wide number of experimental evidences are available regarding oxidant-antioxidant disturbance in hypertension, clinical data supporting it is lacking in men in early stages of hypertension. AIMS: The objective of the study was to evaluate oxidative status and antioxidant activities in males with stage I essential hypertension. MATERIALS AND METHODS: Thirty hypertensives and 21 normotensives were included in the study. Protein carbonyl, reduced glutathione, glutathione peroxidase, catalase and fasting glucose were assessed in both the groups. STATISTICAL ANALYSIS: Results were analyzed by student's ' $t$ ' test and linear regression analysis test. RESULTS: Plasma protein carbonyl and glutathione peroxidase were significantly increased, and catalase and GSH were significantly reduced in the hypertensive group compared to normotensive subjects. There was a significant negative correlation between glutathione peroxidase and catalase in the test group. CONCLUSIONS: The data from the present study indicates an alteration in oxidantantioxidant status in non-obese men in early stages of essential hypertension.

Key words: Antioxidants, essential hypertension, oxidative stress

The prevalence of hypertension has been! increasing in developing countries; and ! community surveys have documented that it ! is more prevalent among the Indians between ! the third and sixth decades of their life. ${ }^{[1] !}$ Hypertension is a major modifiable risk factor ! for cardiovascular disease, which accounts! for 57 and $24 \%$ of all deaths due to stroke and ! coronary heart disease respectively. ${ }^{[2]}$ !

Department of Biochemistry, *Physiology and!

${ }^{* *}$ Medicine, Jawaharlal Institute of Postgraduate!

Medical Education and Research, Pondicherry, India!

Correspondence:

Dr. Zachariah Bobby,!

Department of Biochemistry, JIPMER, Pondicherry - 605006,!

India. E-mail: zacbobby @yahoo.com!
Oxidative stress, which results from either ! overproduction of free radicals or depletion of ! antioxidant reserve, has been implicated in ! the development of cardiovascular disorders ! including hypertension. ${ }^{[3]}$ Previous !studies! have assessed oxidative stress byproducts like! protein carbonyls and antioxidant activities in ! elderly hypertensive subjects and indicated an ! altered oxidant-antioxidant balance in them. ${ }^{[4]}$ ! This hypothesis has been supported by several! experimental studies, which documented an! increased oxidative stress in animal models ! - like renovascular hypertension and obesity-! related hypertension ${ }^{[5,6]}$ - and its subsequent ! reduction on treatment with antioxidants. ${ }^{[7] !}$ 
It has been reported that at young age the ! [systolic blood pressure (SBP $\mathrm{mm} \mathrm{Hg}$ ) $=140-$ ! prevalence of hypertension is higher among ! 159 or diastolic blood pressure (DBP $\mathrm{mm} \mathrm{Hg}$ )! males compared to females. ${ }^{[1]}$ This can be ! = 90-99] and 21 normotensive (SBP $<120$ ! attributed to the fact that females are more ! $\mathrm{mmHg}$ and DBP $<80 \mathrm{~mm} \mathrm{Hg}$ ) men in the age ! protected from oxidative stress through ! group of 25-55 years were enrolled in the study. ! estrogen.$^{[8]}$ Since the reports related to oxidant-! Subjects with history of diabetes, renal disease, ! antioxidant disturbance in men with moderate! endocrine dysfunction, coronary heart disease, ! (stage I) essential hypertension are lacking, ! after infections, smokers and alcoholic and ! the present study was undertaken to evaluate ! those who were on any kind of medication were ! oxidative stress parameters such as protein! excluded from the study. A written informed! carbonyls and antioxidant enzymes in relatively ! young male essential hypertensive subjects.

\section{MATERIALS AND METHODS}

The current study was conducted in the ! Department of Biochemistry and the Department ! of Physiology, JIPMER, Pondicherry. Our subjects included the nonteaching staff ! belonging to our institute and outpatients ! who visited our laboratory for blood pressure check-up. Blood pressure was measured using ! a mercury sphygmomanometer (Diamond, India) with the patients in the sitting position after $5 \mathrm{~min}$ of rest in a quiet environment - according to the recommendations of the ! British Hypertension Society. They were classified as normotensive and hypertensives as per the recommendation of the Joint National ! Committee (JNC) 7 report. ${ }^{[9]}$ Newly diagnosed ! hypertensive subjects were defined as subjects ! who were diagnosed with a sustained elevation ! of blood pressure during the course of the study ! and were neither taking any medications nor were under any form of lifestyle modification. If ! the systolic and diastolic blood pressure were! in different categories, the higher of the two ! was used in the classification.

Thirty newly diagnosed stage I hypertensive !

and hemoglobin. Plasma was collected by ! centrifuging rest of the sample at 5,000 rotation! per minute (rpm) for $5 \mathrm{~min}$ at $4^{\circ} \mathrm{C}$ and was used! for the estimation of protein carbonyl, lipid! profile parameters and glucose. Erythrocytes ! were washed with $0.9 \%$ saline and lysed with ! cold distilled water. Antioxidant enzymes were ! estimated using the lysate.

Whole blood glutathione (GSH) was ! estimated using Ellman's reagent by Beutle's ! method. ${ }^{[10]}$ Hemoglobin levels were estimated! spectrophotometrically at $546 \mathrm{~nm}$ by using ! Drabkin's reagent (E. Merck, Mumbai, India).

Erythrocyte glutathione peroxidase and catalase ! were estimated by methods of Wendel et al. and Aebi et al. respectively. ${ }^{[11,12]}$ Protein ! carbonyl was estimated by Dinitrophenylhydrazine! method. ${ }^{[13]}$ Fasting glucose, total cholesterol ! and triglycerides were estimated by enzymatic ! methods and HDL cholesterol was estimated! by the 'phosphotungstate magnesium acetate' ! method using reagent kits (Agappe's Diagnostics, ! India) adapted to 550 express plus random ! access autoanalyzer (West pole, Canada). ! LDL cholesterol was calculated by Friedwald's ! formula. Fasting insulin was estimated by ! radioimmunoassay (RIAK-1 kit, Board of Radiation! and Isotope Technology, Mumbai) using gamma ! counter (Wallac, Germany).

\section{Statistical analysis}

The results were expressed as mean (S.D.) ! and analyzed by using student's ' 1 ' test. Linear ! regression analysis was used to assess the association between oxidants and antioxidants. ! A !P value of less then 0.05 was considered! significant.

\section{RESULTS}

carbonyl and glutathione peroxidase were ! significantly increased, and catalase and GSH ! were significantly decreased in hypertension.! Since diabetes and obesity are commonly ! associated with hypertension, we estimated! BMI and fasting plasma glucose in both the ! groups and found that there was no significant! difference in these parameters between! the two groups. These findings suggest a ! state of oxidative stress in nondiabetic and! non-obese hypertensive subjects. Also in ! the hypertension group, fasting insulin, total ! cholesterol, triglycerides and LDL cholesterol! were significantly increased, and HDL! cholesterol was significantly decreased in! comparison with control.

Table 1 shows mean and standard deviation of age, BMI, protein carbonyl, antioxidants, ! fasting insulin and lipid profile parameters in hypertensive subjects and controls. Protein !

Figure 1 shows linear

gression analysis of catalase and glutathione peroxidase, which ! was found to be significant ( $\beta=-0.444, R^{2}$ ! $=0.197, P=0.014)$. These results show an ! altered antioxidant status in early stages of ! hypertension.

Table 1: Mean and standard deviation of age, blood pressure, fasting glucose, BMI, fasting insulin, lipid profile, protein carbonyl and antioxidants in hypertensive subjects and controls

\begin{tabular}{|c|c|c|c|c|c|}
\hline Parameters & Control $(n=21)$ & Hypertension $(n=30)$ & $P$ value & 95\% Cl lower & $95 \% \mathrm{Cl}$ upper \\
\hline Systolic blood pressure $(\mathrm{mm} \mathrm{Hg}) !$ & $114 \pm 4 !$ & $141 \pm 10 !$ & $<0.001$ ! & $-31.34 !$ & $-22.05 !$ \\
\hline Diastolic blood pressure $(\mathrm{mm} \mathrm{Hg})$ ! & $72 \pm 4 !$ & $92 \pm 4 !$ & $<0.001$ ! & $-22.14 !$ & $-17.50 !$ \\
\hline Age (yrs)! & $36 \pm 11 !$ & $42 \pm 12 !$ & $0.100 !$ & $-11.76 !$ & $1.07 !$ \\
\hline BMI $\left(\mathrm{kg} / \mathrm{m}^{2}\right) !$ & $23.57 \pm 3.21 !$ & $24.86 \pm 2.24 !$ & $0.097 !$ & $-2.82 !$ & $0.24 !$ \\
\hline Waist/Hip ratio! & $0.91 \pm 0.06 !$ & $0.94 \pm 0.04 !$ & $0.076 !$ & $-0.05 !$ & $-0.003 !$ \\
\hline Plasma Glucose (mg/dl)! & $85.66 \pm 18.85 !$ & $93.00 \pm 13.58 !$ & $0.112 !$ & $-16.45 !$ & $1.78 !$ \\
\hline $\mathrm{GSH}(\mathrm{mg} / \mathrm{gHb})$ & $3.68 \pm 1.50 !$ & $2.76 \pm 1.24 !$ & $0.021 !$ & $0.14 !$ & $1.69 !$ \\
\hline Glutathione -Peroxi & $74.13 \pm 44.02 !$ & & & $-58.54 !$ & $-4.43 !$ \\
\hline Catalase $(\mathrm{k} / \mathrm{ml})$ & $27.92 \pm 14.08 !$ & $19.81 \pm 9.7 !$ & $0.019 !$ & $1.41 !$ & $14.81 !$ \\
\hline Protein carbonyl (nmol/mg protein) ! & $1.85 \pm 0.68 !$ & $2.36 \pm 0.73 !$ & 0.017 ! & $-0.91 !$ & $-0.09 !$ \\
\hline Total protein (g/dl)! & $5.2 \pm 0.84 !$ & $4.59 \pm 1.80 !$ & $0.133 !$ & $-0.20 !$ & $1.49 !$ \\
\hline Fasting Insulin $(\mu \mathrm{u} / \mathrm{ml})$ ! & $21.79 \pm 10.48 !$ & $42.07 \pm 28.74 !$ & $0.003 !$ & $-33.48 !$ & $-7.06 !$ \\
\hline Total cholesterol (mg/dl) ! & $170.80 \pm 27.18 !$ & $=36.20 !$ & 0.0 & $-38.15 !$ & -0.62 \\
\hline Figlycerid & $106.85 \pm 54.80 !$ & $\pm 60.84 !$ & 0.0 & $-68.86 !$ & $-2.02 !$ \\
\hline HDL- chole & $3 \pm$ & $12.41 !$ & 0. & & 17.19 \\
\hline LDL- cholesterol $(\mathrm{mg} / \mathrm{d}$ & $99.57 \pm 29$. & $122.36 \pm 33.65 !$ & $0.016 !$ & $-41.08 !$ & $-4.50 !$ \\
\hline VLDL- cholesterol (mg/dl) ! & $20.85 \pm 10.41 !$ & $28.43 \pm 12.10 !$ & $0.024 !$ & $-14.11 !$ & $-1.03 !$ \\
\hline
\end{tabular}




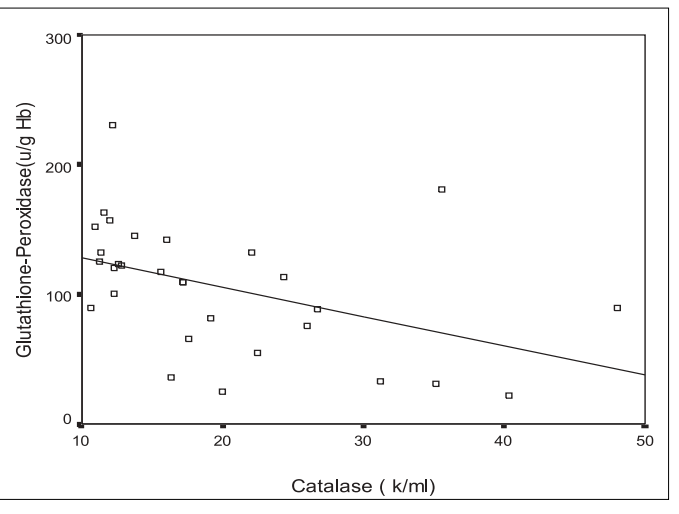
Figure 1: Linear regression analysis of catalase and !
glutathione peroxidase among hypertensive subjects ! $\left(\beta=-0.444, \mathrm{R}^{2}=0.197, P=0.014\right)$ !

\section{DISCUSSION}

Oxidative stress has been implicated in ! the pathogenesis of various cardiovascular! disorders including hypertension. Oxidative ! stress stimulates vascular smooth muscle ! proliferation and reduces nitric oxide ! bioavailability, causing endothelial dysfunction, ! which plays a crucial role in the pathogenesis ! of hypertension by reducing endothelium-! dependent vasodilatation. ${ }^{[14,15] !}$

In contrast with the huge number of ! experimental studies, clinical studies supporting! the involvement of oxidative stress in the pathogenesis of essential hypertension are lacking. In the present study, oxidative stress ! markers such as protein carbonyls were significantly increased in hypertensive cases compared to controls. This finding was supported by previous studies which reported! increased protein carbonyls in different stages ! of hypertension. ${ }^{[16]}$ Increase in plasma protein ! carbonyl in this study indicates that 'free radical'-mediated oxidative damage of proteins ! occurs at an early stage of hypertension and could increase significantly in later stages.

Antioxidant defense mechanisms are altered in ! response to generation of free radicals. Several! investigators have reported contradictory ! findings regarding antioxidant status in essential! hypertension. ${ }^{[4,16]}$ In our study, we found a ! significant increase in erythrocyte glutathione! peroxidase (GPX) levels and reduction in ! catalase and GSH levels. Also, we found ! considerable negative correlation between ! catalase and glutathione peroxidase. The ! primary catalytic cellular defense that protects ! cells and tissues against lipid peroxidation is the ! glutathione peroxidase enzyme. ${ }^{[17]}$ It has been ! observed that glutathione peroxidase can be ! rapidly induced in some conditions when cells ! or organisms are exposed to oxidative stress. ${ }^{[18]}$ ! The increased glutathione peroxidase activity ! in red blood cells of the test subjects may be ! interpreted as a compensatory mechanism due ! to the increased oxidative stress. !

The levels of glutathione peroxidase may be ! related to the stages of hypertension. There are! no reports which point out whether oxidative! stress sets in first or hypertension. The decrease ! in catalase activity in our study may be attributed! to its inactivation as a result of continuous ! exposure to hydroperoxides and hydrogen! peroxide. This decrease can also be due to a ! down-regulation of its expression. The depletion! of glutathione and the accumulation of free ! radicals could induce the enhanced expression! of glutathione peroxidase, as observed in the ! present study. This decrease in catalase and ! an increase in glutathione peroxidase explain ! the negative correlation found between them. Because it has been shown that glutathione! peroxidase is more potent on a molar basis ! than catalase and other antioxidant enzymes ! to protect cells from oxidative stress, ${ }^{[19]}$ it ! can be hypothesized that body tends to ! combat stress by overexpressing glutathione ! peroxidase gene as the first line of defense ! in essential hypertension. As the severity of ! hypertension advances into stage II and III, even ! the defenses of glutathione peroxidase may! deteriorate because of the increased production! of free radicals. This may be the reason for the ! decreased levels of glutathione peroxidase ! observed by Kedziora et al. ${ }^{[4] !}$

\section{CONCLUSION}

Our results point towards an imbalance in ! the oxidant / antioxidant ratio in hypertensive ! patients. Although more than one factor is! implicated in the development of hypertension, ! the hypothetical role of oxidative stress per se! in the development of hypertension cannot be! ruled out. Future epidemiological, polymorphic ! studies to identify candidate antioxidant genes ! that are altered in essential hypertension are ! warranted. This will increase our understanding ! of the genetic modulation of antioxidant ! enzymes in these subjects, which will be useful ! for the development of molecular interventions ! in them. Further studies are also required! to define whether dietary or supplemental ! antioxidants ameliorate these processes.

\section{ACKNOWLEDGMENTS}

This work was supported by a financial grant ! from the Department of Science and Technology, ! Pondicherry. This work was also supported by ! Council for Scientific and Industrial Research in ! the form of Senior Research Fellowship for Ms. V. Sathiyapriya.

\section{REFERENCES}

1. !Das SK, Sanyal K, Basu A. Study of urban! community survey in India: Growing trend of high ! prevalence in developing country. Int J Med Sci ! 2005;2:70-8.

2. ! Gupta R. Trends in hypertension epidemiology in ! India. J Hum Hypertens 2004;18:73-8.

3. ! Ogita H, Liao J. Endothelial function and oxidative ! stress. Endothelium 2004;11:123-32.

4. !Kedziora-Kornatowska K, Czuczejko J, Pawluk ! H, Kornatowski T, Motyl J, Szadujkis-Szadurski L, ! et al. The markers of oxidative stress and activity ! of the antioxidant system in the blood of elderly ! patients with essential arterial hypertension. Cell ! Mol Biol Lett 2004;9:635-41.

5.! Lerman LO, Nath KA, Rodriguez-Porcel M, Krier ! JD, Schwartz RS, Napoli C, et al. Increased! oxidative stress in experimental renovascular! hypertension, Hypertension 2001;37:541-6.

6. Dobrian AD, Davies MJ, Schriver SD, Lauterio ! TJ, Prewitt RL. Oxidative stress in a rat model ! of obesity induced hypertension. Hypertension! 2001;37:554-60.

7. !Racasan S, Braam B, Van der Giezen DM, ! Goldschmeding R, Boer P, Koomans HA, et al. Perinatal L-arginine and antioxidant supplements ! reduce adult blood pressure in spontaneously ! hypertensive rats. Hypertension 2004;44:83-8.

8. !Busserolles J, Mazur A, Gueux E, Rock E, ! Rayssiguier $\mathrm{Y}$. Metabolic syndrome in the rat: ! Females are protected against the pro-oxidant! effect of a high sucrose diet. Exp Biol Med! 2002;227:837-42.

9. ! Chobanian AV, Bakris GL, Black HR, Cushman! WC, Green LA, Izzo JL, et al. Seventh report of the ! joint national committee on prevention, detection, ! evaluation and treatment of high blood pressure. Hypertension 2003;42:1206-52.

10. Beutle E, Duron O, Kelly BM. Improved method! for the determination for blood glutathione. J Lab ! Clin Med 1963;61:882-8.

11. Wendel A. Glutathione peroxidase. Methods ! 
Enzymol 1981;77:325-33.

12. Aebi H. Catalase in vitro. Methods Enzymol ! 1984;105:121-6.

13. Reznick AZ, Packer L. Oxidative damage to ! proteins: Spectophotometric method for carbonyl! assay. Methods Enzymol 1994;233:357-63.

14. Panza JA, Quyyumi AA, Brush JE Jr, Epstein ! SE. Abnormal endothelium dependent vascular! relaxation in patients with essential hypertension. ! N Engl J Med 1990;323:22-7.

15. Griendling KK, Sorescu D, Ushio-Fukai M. ! $\mathrm{NAD}(\mathrm{P}) \mathrm{H}$ oxidase: Role in cardiovascular biology ! and disease. Circ Res 2000;86:494-501.

16. Simic DV, Mimic-Oka J, Pljesa-Ercegovac M, ! Savic-Radojevic A, Opacic M, Matic D, et al. Byproducts of oxidative protein damage and ! antioxidant enzyme activities in plasma of patients ! with different degrees of essential hypertension.
J Hum Hypertens 2006;20:149-55.

17. Cohen G, Hochstein P. Glutathione peroxidase: ! The principle agent for the elimination of hydrogen! peroxidase in erythrocytes. Biochemistry ! 1963;2:1420-8.

18. Lu D, Maulik N, Moraru II, Kreutzer DL, Das DK. ! Molecular adaptation of vascular endothelial cells ! to oxidative stress. Am J Physiol 1993;264:C715-!

22.

19. Michiels C, Toussaint O, Remacle J. Comparative ! study of oxygen toxicity on human fibroblasts and ! endothelial cells. J Cell Physiol 1990;144:295-! 302.

Source of Support: Department of Science and Technology, ! Pondicherry. and Council for Scientific and Industrial Research in the form of Senior Research Fellowship for Ms. V. Sathiyapriya., ! Conflict of Interest: None declared.

\section{Author Help: Online Submission of the Manuscripts}

Articles can be submitted online from http://www.journalonweb.com. For online submission articles should be prepared in two files (first page file and article file). Images should be submitted separately.

1) First Page File:

Prepare the title page, covering letter, acknow ledgement, etc., using a w ord processor program. All information which can reveal your identity should be here. Use text/rtf/doc/pdf files. Do not zip the files.

2) Article file:

The main text of the article, beginning from Abstract till References (including tables) should be in this file. Do not include any information (such as acknow ledgement, your names in page headers, etc.) in this file. Use text/ rtf/doc/pdf files. Do not zip the files. Limit the file size to $400 \mathrm{~kb}$. Do not incorporate images in the file. If file size is large, graphs can be submitted as images separately without incorporating them in the article file to reduce the size of the file.

3) Images:

Submit good quality colour images. Each image should be less than $\mathbf{4 0 0} \mathbf{~ k b}$ in size. Size of the image can be reduced by decreasing the actual height and width of the images (keep up to about 4 inches) or by reducing the quality of image. All image formats (jpeg, tiff, gif, bmp, png, eps, etc.) are acceptable; jpeg is most suitable. The image quality should be good enough to judge the scientific value of the image.

Always retain a good quality, high resolution image for print purpose. This high resolution image should be sent to the editorial office at the time of sending a revised article.

4) Legends:

Legends for the figures/images should be included at the end of the article file. 